\title{
Augmented Cocaine Seeking in Response to Stress or CRF Delivered into the Ventral Tegmental Area Following Long-Access Self-Administration Is Mediated by CRF Receptor Type 1 But Not CRF Receptor Type 2
}

\author{
Jordan M. Blacktop, Chad Seubert, David A. Baker, Nathan Ferda, Geng Lee, Evan N. Graf, and John R. Mantsch \\ Department of Biomedical Sciences, Marquette University, Milwaukee, Wisconsin 53201
}

\begin{abstract}
Stressful events are determinants of relapse in recovering cocaine addicts. Excessive cocaine use may increase susceptibility to stressorinduced relapse through alterations in brain corticotropin-releasing factor (CRF) regulation of neurocircuitry involved in drug seeking. We previously reported that the reinstatement of cocaine seeking by a stressor (footshock) is CRF dependent and is augmented in rats that self-administered cocaine under long-access ( $\mathrm{LgA} ; 6 \mathrm{~h}$ daily) conditions for $14 \mathrm{~d}$ when compared with rats provided shorter daily cocaine access [short access $(\mathrm{ShA})$ rats; $2 \mathrm{~h}$ daily]. Further, we have demonstrated that reinstatement in response to intracerebroventricular CRF administration is heightened in $\mathrm{LgA}$ rats. This study examined the role of altered ventral tegmental area (VTA) responsiveness to CRF in intake-dependent increases in CRF- and stress-induced cocaine seeking. Bilateral intra-VTA administration of CRF ( $250 \mathrm{or} 500 \mathrm{ng} / \mathrm{side}$ ) produced reinstatement in LgA but not ShA rats. In LgA rats, intra-VTA CRF-induced reinstatement was blocked by administration of the CRF-receptor type 1 (CRF-R1) antagonist antalarmin (500 ng/side) or CP-376395 (500 ng/side), but not the CRF-R2 antagonist astressin-2B (500 ng or $1 \mu \mathrm{g} / \mathrm{side}$ ) or antisauvagine-30 (ASV-30; $500 \mathrm{ng} / \mathrm{side}$ ) into the VTA. Likewise, intra-VTA antalarmin, but not astressin-2B, blocked footshock-induced reinstatement in LgA rats. By contrast, neither intra-VTA antalarmin nor CP-376395 altered food-reinforced lever pressing. Intra-VTA injection of the CRF-R1-selective agonist cortagine (100 ng/side) but not the CRF-R2-selective agonist rat urocortin II (rUCN II; $250 \mathrm{ng} /$ side) produced reinstatement. These findings reveal that excessive cocaine use increases susceptibility to stressor-induced relapse in part by augmenting CRF-R1-dependent regulation of addiction-related neurocircuitry in the VTA.
\end{abstract}

\section{Introduction}

Cocaine addiction is associated with a persistent susceptibility to drug relapse that emerges in an intake-dependent manner with repeated use. Understanding the neurobiological mechanisms that underlie drug relapse in cocaine addicts is critical to the development of effective treatment. Much evidence suggests that stress contributes to relapse. Stress promotes craving in abstinent human cocaine addicts (Sinha et al., 1999) and precipitates reinstatement in rodent relapse models (Erb et al., 1996; Ahmed and Koob, 1997).

The preclinical study of addiction-related, drug-induced neuroplasticity has involved the use of the long-access selfadministration approach (Ahmed and Koob, 1998) in which rats provided repeated daily long access (LgA) to cocaine for self-

\footnotetext{
Received March 17, 2011; revised June 22, 2011; accepted June 23, 2011.

Author contributions: J.M.B., D.A.B., and J.R.M. designed research; J.M.B., C.S., N.F., G.L., E.N.G., and J.R.M. performed research; J.R.M. analyzed data; J.R.M. wrote the paper.

This work was supported by National Institute on Drug Abuse Grants DA15758 and DA025617. We acknowledge Michael Hoks and Chris Mueller for their technical assistance.

The authors declare no competing financial interests.

Correspondence should be sent to Dr. John R. Mantsch, Department of Biomedical Sciences, Box 1881, Marquette University, Milwaukee, WI 53201-1881. E-mail: john.mantsch@marquette.edu.

DOI:10.1523/JNEUROSCI.1393-11.2011

Copyright $\odot 2011$ the authors $\quad 0270-6474 / 11 / 3111396-08 \$ 15.00 / 0$
}

administration (6-10 h/daily) are compared with rats provided shorter daily drug access [short access (ShA); 1-2 h/d]. We have reported that, compared with ShA rats, LgA rats are more susceptible to reinstatement by a stressor, footshock, suggesting that repeated cocaine use can produce intake-dependent alterations in how stress regulates neurocircuitry subserving motivation and relapse susceptibility (Mantsch et al., 2008). Our findings are consistent with reports that the magnitude of stress-induced craving is influenced by the amount of prior use in human addicts (Fox et al., 2005).

The neuropeptide, corticotropin releasing factor (CRF), is a key mediator of stress-induced cocaine seeking (Shalev et al., 2010). CRF receptor antagonists block stress-induced reinstatement (Erb et al., 1998; Shaham et al., 1998; Graf et al., 2011), while delivery of CRF directly into the brain reinstates cocaine seeking (Erb et al., 2006; Mantsch et al., 2008). One key site at which CRF promotes reinstatement is the ventral tegmental area (VTA) (Wise and Morales, 2010) where CRF delivery precipitates reinstatement following selfadministration (Wang et al., 2005, 2007). The VTA receives CRFcontaining projections from a number of brain regions (Rodaros et al., 2007), and in vivo microdialysis studies have found that, during footshock-induced reinstatement, VTA extracellular CRF levels are elevated (Wang et al., 2005). 
A
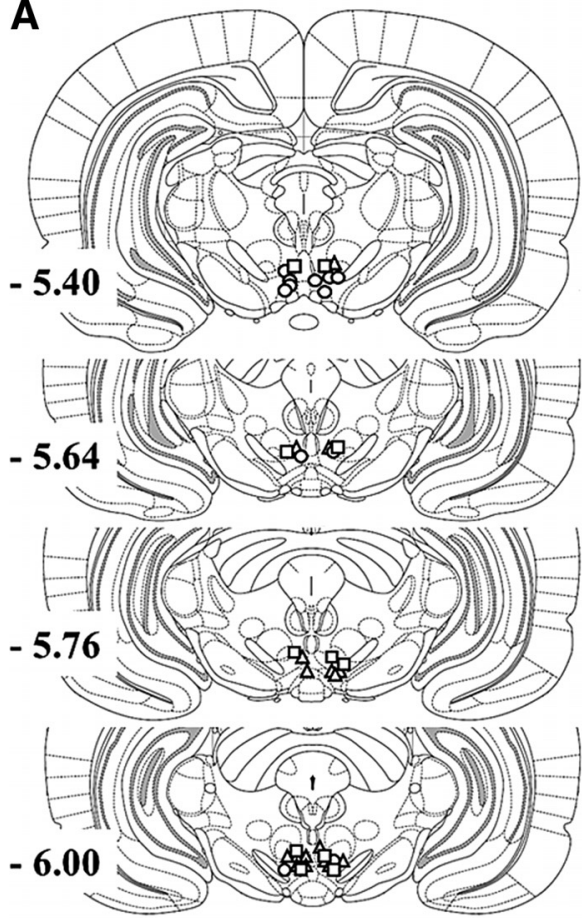

B
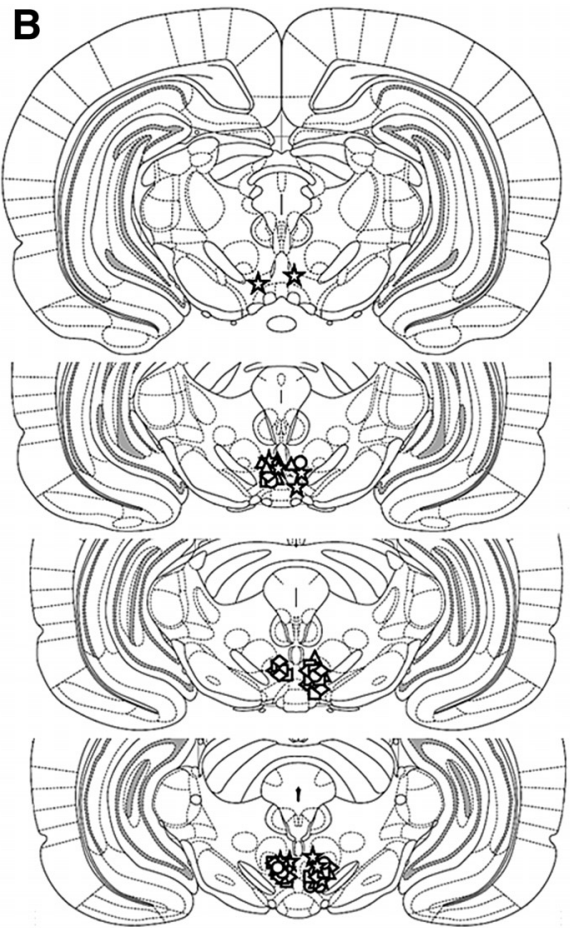
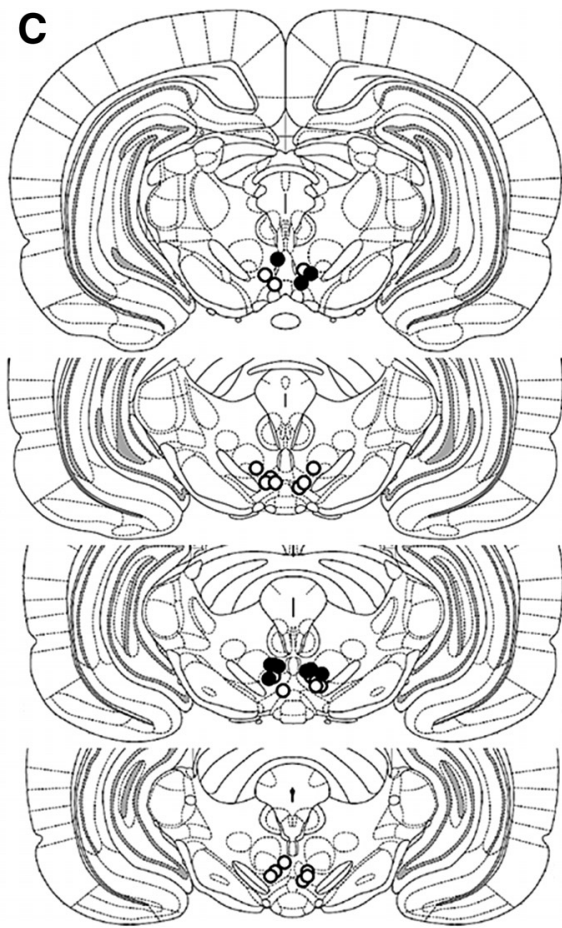

Figure 1. $\boldsymbol{A}-\boldsymbol{C}$, Injection sites within the VTA for the following: LgA rats (triangles), ShA rats (squares), and Sal rats (circles) (A); LgA rats tested for CRF-induced reinstatement following (P-376395 (triangles), ASV-30 (circles), antalarmin (diamonds), and astressin-2B (squares), or LgA rats tested for footshock-induced reinstatement (stars) (B); and rats tested for effects on food-reinforced responding (open circles) and LgA rats tested for reinstatement by CRF receptor agonists (closed circles) (C).

Although both CRF-R1 and CRF-R2 subtypes have been reported to be expressed in the VTA, the degree of expression, cellular localization, and function of these receptors in the VTA is controversial, and the receptor mechanism through which CRF regulates cocaine seeking remains unclear. Wang et al. (2005, 2007) have reported that reinstatement by intra-VTA CRF involves an activation of CRF-R2s that relies on an interaction with CRF binding protein, consistent with the mechanism through which CRF acutely enhances NMDA receptor-mediated currents in the VTA (Ungless et al., 2003). However, others have found that stress-induced reinstatement and evoked increases in VTA and nucleus accumbens (NAc) dopamine rely on CRF-R1 and not CRF-R2 (Shaham et al., 1998; Lu et al., 2001, 2003).

We have reported that reinstatement by centrally administered CRF is also augmented following LgA drug selfadministration, suggesting that enhanced CRF responsiveness contributes to heightened stress-induced relapse (Mantsch et al., 2008). In this study, we examine intake-dependent augmentation of intra-VTA CRF-induced reinstatement and the role of VTA CRF-R1 versus CRF-R2 in reinstatement in response to CRF and stress.

\section{Materials and Methods}

Adult male Sprague Dawley rats (Harlan Laboratories) were housed individually under a $12 \mathrm{~h}$ reversed light/dark cycle (lights on at 7:00 P.M.) in a temperature and humidity controlled Association for Assessment and Accreditation of Laboratory Animal Care-accredited animal facility. All procedures were approved by the Marquette University Institutional Animal Care and Use Committee and performed in accordance with the NIH Guide for the Care and Use of Laboratory Animals.

Catheter and cannula implantation. For the reinstatement studies, rats were implanted with chronic indwelling jugular catheters under ketamine $\mathrm{HCl}(100 \mathrm{mg} / \mathrm{kg}$, i.p. ) and xylazine $(2 \mathrm{mg} / \mathrm{kg}$, i.p. $)$ anesthesia, as previously described (Mantsch et al., 2008; Graf et al., 2011), and with bilateral $11 \mathrm{~mm} 26$ gauge guide cannulae aimed at the VTA for intracranial injections. The tips of the guide cannulae were aimed $0.5 \mathrm{~mm}$ above the target injection site using the following coordinates determined from Paxinos and Watson (1998): $12^{\circ}$ angle away from midline; anteroposterior $-5.6 \mathrm{~mm}$ from bregma; mediolateral $+2.2 \mathrm{~mm}$ from midline; and dorsoventral $-6.7 \mathrm{~mm}$ from the skull surface. Placements for cannulae targeting the VTA for rats from each of the experiments are depicted in Figure 1.

Self-administration training. After recovery from surgery, rats were trained to self-administer cocaine $(1.0 \mathrm{mg} / \mathrm{kg} /$ infusion, i.v.; NIDA Drug Supply Program) by pressing a lever under a fixed ratio 1 (FR1) schedule during daily $2 \mathrm{~h}$ sessions, within which the active (i.e., front) lever was extended into the chamber and the corresponding stimulus light was illuminated. Pressing the lever resulted in an intravenous infusion of drug or saline (Sal) solution ( $200 \mu$ l over $5 \mathrm{~s})$ followed by a $25 \mathrm{~s}$ time-out period during which the stimulus light was extinguished but the lever remained extended. Responding on a second, inactive (i.e., back) lever was recorded but had no programmed consequences. Response requirements were gradually increased until rats displayed stable responding (within 10\% of the three session mean) under an FR4 schedule, at which time they entered into a 14 day period of self-administration testing.

Effects of LgA self-administration on intra-VTA CRF-induced reinstatement. To examine intake-dependent effects of cocaine self-administration on later reinstatement by intra-VTA CRF, rats were assigned to ShA or LgA groups after self-administration training according to their access conditions for cocaine self-administration for the next $14 \mathrm{~d}$. ShA rats $(n=6)$ continued to have access to cocaine for $2 \mathrm{~h}$ daily, as described above. LgA rats $(n=8)$ had access to the same cocaine dose for $6 \mathrm{~h}$ daily. Additionally, a third group of rats with no history of cocaine selfadministration had access to infusions of saline during 14 daily $2 \mathrm{~h}$ sessions and served as a control to examine nonspecific effects of intra-VTA CRF on lever pressing $(n=6)$. Following $14 \mathrm{~d}$ of self-administration, rats underwent extinction during 10 consecutive $2 \mathrm{~h}$ sessions within which the cocaine solution was replaced by saline. After extinction, rats received a bilateral sham intra-VTA injection before testing for reinstatement in response to bilateral intra-VTA delivery of CRF (250 or $500 \mathrm{ng} / \mathrm{side}$; 
Sigma-Aldrich) or vehicle (Veh) $(0.9 \% \mathrm{NaCl})$ delivered in a volume of $0.25 \mu \mathrm{l} /$ side over a $1 \mathrm{~min}$ period $10 \mathrm{~min}$ before the reinstatement session. Responding on both the cocaine and inactive levers was recorded during the $2 \mathrm{~h}$ reinstatement sessions, which were otherwise identical to extinction conditions. The order of testing with the two CRF doses and vehicle varied across rats in each group to avoid potential sequence effects. Rats underwent additional extinction sessions between reinstatement test sessions and were required to display $<20$ cocaine lever responses during an intervening extinction session to be tested again for reinstatement.

Effects of CRF receptor antagonists on intra-VTA CRF-induced reinstatement. To examine the role of CRF-R1 and CRF-R2 in reinstatement by intra-VTA administration of CRF, the ability of CRF (500 ng/side) to reinstate cocaine seeking following a $15 \mathrm{~min}$ bilateral intra-VTA pretreatment $(0.25 \mu \mathrm{l} /$ side over $1 \mathrm{~min})$ with the CRF-R1-selective antagonists antalarmin ( $500 \mathrm{ng} / \mathrm{side}$; Sigma Aldrich; $n=7$ ) (Webster et al., 1996) or CP-376395 (500 ng/side; Tocris Biosciences; $n=6$ ) (Chen et al., 2008), or the CRF-R2-selective antagonists astressin-2B (500 ng and $1 \mu \mathrm{g} / \mathrm{side}$; Sigma-Aldrich; $n=6$ ) or antisauvagine-30 (ASV-30; 500 ng/side; SigmaAldrich; $n=6$ ) was determined in separate groups of LgA rats. The astressin-2B and ASV-30 doses that were selected were based on those previously used for intracranial injections (Henry et al., 2006; Forster et al., 2008). After $14 \mathrm{~d}$ of LgA self-administration and extinction, rats were tested twice for CRF-induced reinstatement in counterbalanced sequence: once following intra-VTA pretreatment with CRF receptor antagonist; and once following pretreatment with vehicle. In the case of the CRF-R2 antagonist astressin-2B, rats were also treated with a second, higher antagonist dose $(1 \mu \mathrm{g} /$ side $)$.

Effects of CRF receptor antagonists on stress-induced reinstatement. To examine the role of CRF-R1 and CRF-R2 activation in the VTA in stressinduced reinstatement, separate groups of rats were tested for the ability of electric footshock, delivered though the stainless steel grid floors of the self-administration chambers, to reinstate cocaine seeking following bilateral intra-VTA delivery of the CRF-R1-selective antagonist antalarmin ( $500 \mathrm{ng} / \mathrm{side} ;=7$ ) or the CRF-R2-selective antagonist astressin-2B (500 $\mathrm{ng} / \mathrm{side} ;=8$ ). During the $15 \mathrm{~min}$ footshock period, the houselight was illuminated, the levers were retracted, and stimulus lights extinguished. Shocks $(0.5 \mathrm{~mA}, 0.5 \mathrm{~s}$ duration) were delivered an average of every $40 \mathrm{~s}$ (range, $10-70 \mathrm{~s}$ ). We have reported that these parameters produce robust reinstatement after long-access, but not short-access, self-administration (Mantsch et al., 2008). As was the case with intra-VTA CRF, rats were tested twice for footshock-induced reinstatement in counterbalanced fashion: once following intra-VTA pretreatment with CRF receptor antagonist; and once following pretreatment with vehicle.

Food self-administration. To confirm that the effects of intra-VTA antalarmin and CP-376395 on reinstatement were not attributable to nonspecific motor impairments, rats were tested for effects on sucrose pellet-reinforced lever pressing (data not shown). These rats were maintained at $90 \%$ of their free-feeding body weights and were trained to self-administer $45 \mathrm{mg}$ sucrose-sweetened food pellets (BioServ) by pressing a response lever under an FR4 schedule of reinforcement during 30 min sessions. Once stable response patterns were observed (responding within $10 \%$ of the mean over three sessions), separate groups of rats were tested for the effects of intra-VTA delivery of antalarmin (500 ng/side; $n=10$ ) or CP-376395 (500 ng/side; $n=6$ ), as described above, on responding. Each rat was tested twice with intra-VTA treatment in counterbalanced sequence: once with the CRF-R1 antagonist; and once with vehicle.

Reinstatement by intra-VTA administration of CRF receptor agonist drugs. To further examine the role of CRF-R1 and CRF-R2 in reinstatement, a separate group of $\operatorname{LgA}$ rats $(n=5)$ was tested for reinstatement following bilateral intra-VTA administration of the CRF-R1-selective agonist cortagine (100 ng/side) (Tezval et al., 2004), the CRF-R2selective agonist rat urocortin II (250 ng/side) (Reyes et al., 2001), or vehicle ( $5 \mathrm{~mm}$ acetic acid in sterile saline). Following self-administration and extinction, each rat was tested with each intra-VTA treatment in counterbalanced sequence. After the first test, rats were only tested again for reinstatement if they emitted $<20$ responses during an intervening extinction session.
Histological confirmation of injection sites. The accuracy of cannula implantation was confirmed postmortem in each rat after cardiac perfusion with $60 \mathrm{ml}$ of $\mathrm{NaCl}$ followed by $60 \mathrm{ml}$ of $2.5 \%$ buffered neutral formalin under sodium barbital anesthesia $(55 \mathrm{mg} / \mathrm{kg})$. Brains were removed and stored in $2.5 \%$ buffered formalin for at least $1 \mathrm{~d}$. Two hundred micrometer sections were cut using a vibrotome, slide-mounted, and stained with cresyl violet for placement confirmation using a light microscope. Rats with injection sites outside of the VTA were excluded from data analysis. Notably, in cases where the injection sites were outside of the VTA (eight rats), bilateral intracranial delivery of the 500 $\mathrm{ng} /$ side CRF dose failed to produce significant reinstatement (mean responses, $20.38 \pm 5.51$ vs $47.50 \pm 7.20$ for rats with injection sites within the VTA).

Statistical analyses. Statistical analyses were conducted using Predictive Analytics SoftWare statistics software (SPSS). Statistical significance was determined using ANOVA or Student's $t$ tests followed, when appropriate, by further analyses of main effects using ANOVA and/or post hoc testing using Bonferroni-corrected $t$ tests.

\section{Results}

\section{Effects of self-administration access condition on} reinstatement by intra-VTA CRF self-administration

As expected, escalated self-administration was observed in rats provided daily long access ( $6 \mathrm{~h}$; LgA rats, $n=8)$ but not short access ( $2 \mathrm{~h}$; ShA rats, $n=6$ ) to cocaine for self-administration and was not observed in rats provided access to saline (Sal rats, $n=6$ ). For analysis, the mean daily hourly self-administration (infusions per hour) was compared across groups over the $14 \mathrm{~d}$ time period (Fig. $2 A$ ). Two-way ANOVA examining the effects of self-administration condition (ShA, LgA, and Sal) and day (1-14, repeated-measures) on the hourly number of self-administered infusions showed a significant overall main effect of selfadministration condition $\left(F_{(2,16)}=23.561 ; p<0.001\right)$ but not day, and a significant condition $\times$ day interaction $\left(F_{(26,208)}=\right.$ $2.708 ; p<0.01)$. The daily number of self-administered infusions increased across the $14 \mathrm{~d}$ of self-administration in LgA but not ShA or Sal rats (one-way ANOVA: $F_{(13,78)}=2.520 ; p<0.01$ ). Post hoc testing showed that self-administration was increased in LgA rats on days 5 and $9-14$ compared with ShA rats $(p<0.05$ for each comparison, Bonferroni-corrected $t$ test). The mean net cocaine intake over the 14 sessions was markedly higher in LgA rats compared with ShA rats $\left(t_{(11)}=5.889 ; p<0.001\right)$ and is shown in the inset of Figure $2 \mathrm{~A}$.

\section{Extinction and intra-VTA CRF-induced reinstatement}

Responding did not differ between ShA and LgA rats during the 10 extinction sessions before reinstatement testing (Fig. 2B). However, differences in reinstatement in response to intra-VTA CRF (250 or 500 ng/side) were observed (Fig. 2C). Reinstatement by intra-VTA CRF was only observed in rats with a history of LgA self-administration. Two-way self-administration group (ShA, LgA, Sal) $\times$ reinstatement condition (Veh: $250 \mathrm{ng} /$ side CRF, 500 ng/side CRF) repeated-measures ANOVA showed significant main effects of self-administration group $\left(F_{(2,17)}=16.774 ; p<\right.$ $0.001)$ and reinstatement condition $\left(F_{(2,34)}=7.934 ; p=0.001\right)$, and a significant group $\times$ reinstatement condition interaction $\left(F_{(4,34)}=5.969 ; p=0.001\right)$. CRF-induced increases in responding were only found in rats with a history of LgA selfadministration (one-way repeated-measures ANOVA; $F_{(2,14)}=$ 10.639; $p<0.01)$. Post hoc testing showed that responding following intra-VTA administration of the $500 \mathrm{ng} /$ side CRF dose was significantly increased compared with vehicle $(p<0.05)$. Additionally, responding on the previously active lever was significantly increased in LgA rats compared with ShA and Sal rats 
A

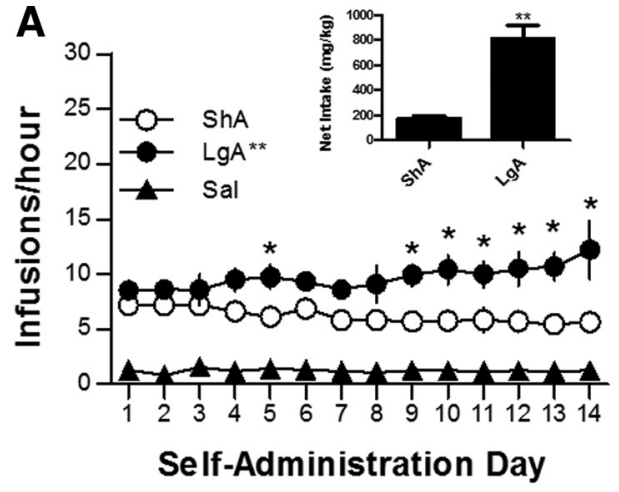

C

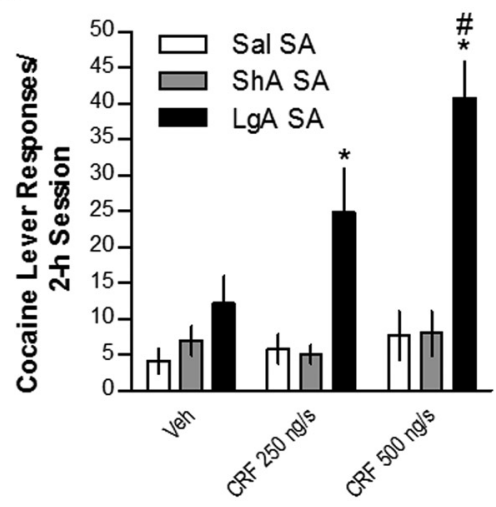

Intra-VTA Treatment
B

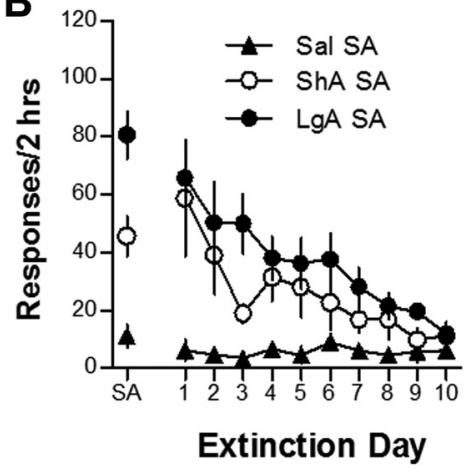

D

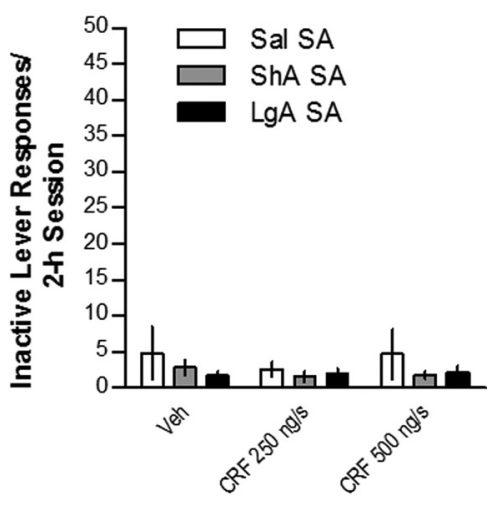

Intra-VTA Treatment

Figure 2. Self-administration, extinction, and reinstatement of cocaine seeking by intra-VTA injections of CRF in ShA ( $14 \times 2$ $\mathrm{h} / \mathrm{d})$ and $\operatorname{LgA}(14 \times 6 \mathrm{~h} / \mathrm{d})$ rats and in saline self-administration control rats. $A$, Data represent the daily mean hourly numbers of self-administered infusions ( $\pm \mathrm{SE}$ ) in ShA, LgA, and Sal rats across the 14 day test period. Escalation was observed in LgA, but not ShA or Sal rats ( ${ }^{* *} p<0.05$ overall effect), and self-administration was increased in LgA rats compared with ShA (and Sal) rats on days 5 and $9-14$ of self-administration $\left({ }^{*} p<0.05\right.$ ). The cumulative total cocaine intake (in milligrams per kilogram \pm SE) in ShA and $\operatorname{LgA}$ rats is shown in the inset in $\boldsymbol{A}$. Intake was markedly and significantly increased in LgA rats ( ${ }^{* *} p<0.001$ vs ShA rats). $\boldsymbol{B}$, Responding ( \pm SE) during the final self-administration session (represented as the $2 \mathrm{~h}$ mean in LgA rats) and the 10 consecutive $2 \mathrm{~h}$ extinctions sessions is shown. Significant differences in extinction responding between ShA and $\mathrm{LgA}$ rats were not found. $\boldsymbol{C}$, Significant intra-VTA CRF-induced reinstatement was observed in LgA but not ShA rats, and CRF-induced responding was significantly higher in LgA rats compared with ShA rats and Sal controls at both doses tested ( ${ }^{*} p<0.05$ ), and increased compared with vehicle at the $500 \mathrm{ng} / \mathrm{side}$ (but not the $250 \mathrm{ng} / \mathrm{side}$ ) CRF dose ( ${ }^{\#} p<0.05$ ). D, Effects on responding on the previously inactive lever during reinstatement testing were not found.

following intra-VTA delivery of either $250 \mathrm{ng} /$ side CRF (one-way ANOVA, $F_{(2,19)}=4.179, p<0.05$; significant increase in LgA vs either ShA or Sal, $p<0.05$, Bonferroni-corrected $t$ test) or 500 ng/side CRF (one-way ANOVA, $F_{(2,19)}=23.103, p<0.001$; significant increase in LgA vs either ShA or Sal, $p<0.05)$. By contrast, we failed to find reinstatement effects or self-administration group effects on responding on the previously inactive lever or a reinstatement $\times$ group interaction (Fig. $2 D$ ).

\section{Effects of intra-VTA CRF-R1 antagonists on CRF-induced reinstatement}

Bilateral intra-VTA pretreatment with the CRF-R1-selective antagonist antalarmin or CP-376395 blocked reinstatement by intra-VTA CRF (500 ng/side) in LgA rats (Fig. 3). The effect of antalarmin on CRF-induced reinstatement $(n=7)$ is shown in Figure $3 A$, and the effect of CP-376395 on CRF-induced reinstatement $(n=6)$ is shown in Figure $3 B$. In both cases, two-way repeated measures (CRF vs extinction; antagonist vs vehicle) ANOVA showed significant main effects of CRF delivery $\left(F_{(1,6)}=12.603, p<0.05\right.$ for antalarmin; $F_{(1,5)}=6.920, p<0.05$ for CP-376395), but not antagonist treat- ment, and significant interactions between CRF-R1 antagonist pretreatment and CRFinduced reinstatement $\left(F_{(1,6)}=5.696, p=\right.$ 0.05 for antalarmin; $F_{(1,5)}=9.120, p<0.05$ for CP-376395). Intra-VTA CRF produced significant reinstatement following pretreatment with vehicle $(p<0.01$ for each experiment), but not antalarmin or $\mathrm{CP}$ 376395, and responding following intraVTA CRF administration was significantly lower following antalarmin or CP-376395 pretreatment compared with vehicle pretreatment $(p<0.01)$.

\section{Effects of intra-VTA CRF-R1 antagonism on stress-induced reinstatement}

Antagonism of CRF-R1 in the VTA also blocked footshock-induced reinstatement in LgA rats $(n=6)$ (Fig. $3 C)$. Two-way (footshock vs extinction; antalarmin vs vehicle) repeated-measures ANOVA showed a significant overall effect of footshock $\left(F_{(1,5)}=28.817, p<0.01\right)$, but not antalarmin pretreatment, and a significant antalarmin $\times$ footshock interaction $\left(F_{(1,5)}=\right.$ $6.294, p=0.05)$. Intra-VTA CRF produced significant reinstatement following pretreatment with vehicle $(p<0.01)$, but not antalarmin, and responding following EFS was significantly lower following antalarmin pretreatment compared with vehicle pretreatment $(p<0.01)$.

\section{Effects of intra-VTA CRF-R1 \\ antagonists on food-reinforced lever pressing}

To confirm that the effects of intra-VTA antalarmin and CP-376395 on reinstatement were not attributable to nonspecific motor impairments, effects on sucrose pellet-reinforced lever pressing were examined. Neither intra-VTA antalarmin $(185.83 \pm 28.86$ responses/30 min session vs $211.80 \pm 13.41$ responses/session for vehicle) nor intra-VTA CP-376395 (192.67 \pm 23.73 responses $/ 30 \mathrm{~min}$ session vs $203.10 \pm 13.17$ responses/session for vehicle) significantly decreased food-reinforced responding at doses that blocked CRF- or footshock-induced reinstatement. When interpreting these findings, it is important to note that in contrast to our self-administration rats, these rats had no history of cocaine intake and were food restricted, possibly altering their sensitivity to CRF-R1 antagonism.

Effects of intra-VTA CRF-R2 antagonists on CRF- and stress-induced reinstatement

The effects of bilateral intra-VTA pretreatment with CRF-R2selective antagonists astressin-2B or ASV-30 on reinstatement by intra-VTA CRF ( $500 \mathrm{ng} /$ side) are shown in Figure $4, A$ and $B$. The effects of the astressin-2B on CRF-induced reinstatement $(n=6)$ are shown in Figure $4 \mathrm{~A}$. We initially tested rats for the effect of astressin-2B at the $500 \mathrm{ng} /$ side astressin-2B dose. However, since this dose of astressin-2B did not attenuate reinstatement, we also tested rats with a twofold higher dose of astressin-2B ( $1 \mu \mathrm{g} / \mathrm{side})$. 
Two-way repeated-measures ANOVA examining the effects of both astressin- $2 \mathrm{~B}$ doses on reinstatement showed a significant overall effect of CRF-induced reinstatement $\left(F_{(1,5)}=52.077, p=0.001\right)$, but not astressin-2B pretreatment, and no significant astressin-2B $\times C R F$ reinstatement interaction. Significant intra-VTA CRF-induced reinstatement was observed in rats pretreated with vehicle or either astressin-2B dose ( $p<0.01$ for each comparison), and reinstatement was not significantly different following astressin-2B delivery when compared with vehicle administration. Likewise, intra-VTA pretreatment with ASV-30 failed to alter reinstatement by intra-VTA CRF $(n=6)$ (Fig. 4B). Two-way repeated-measures ANOVA showed a significant overall effect of CRF-induced reinstatement $\left(F_{(1,5)}\right.$ $=8.462, p<0.05)$, but not ASV-30 pretreatment, and no significant ASV-30 $\times$ CRF reinstatement interaction. Significant intra-VTA CRF-induced reinstatement was observed in rats pretreated with vehicle or ASV-30 $(p<0.01)$, and reinstatement was not different following ASV-30 delivery when compared with vehicle administration.

\section{Effects of intra-VTA CRF-R2 \\ antagonism on stress-induced reinstatement}

Intra-VTA pretreatment with the CRF$\mathrm{R} 2$-selective antagonist astressin-2B also failed to alter footshock-induced reinstatement $(n=8)$ (Fig. 4C). As was the case with CRF-induced reinstatement, ANOVA showed a significant overall effect of footshock reinstatement $\left(F_{(1,7)}=20.587, p<\right.$ 0.01 ), but not astressin-2B pretreatment, and no significant interaction. Significant footshock-induced reinstatement was observed in rats pretreated with vehicle or astressin-2B $(p<0.01)$, and reinstatement was not different following astressin-2B delivery when compared with vehicle.

\section{Reinstatement by intra-VTA administration of the CRF receptor agonists}

To further examine the role of VTA CRF-R1 and CRF-R2 in reinstatement, the ability of bilateral intra-VTA injection of the selective CRF-R1 agonist cortagine (100 ng/side) or the selective CRF-R2 agonist rUCN II ( $250 \mathrm{ng} /$ side) to reinstate cocaine seeking was examined in a separate group of LgA rats $(n=5)$ (Fig. 5). Reinstatement was observed following intra-VTA delivery of cortagine but not rUCN II. A two-way repeated-measures ANOVA with reinstatement condition (extinction vs intra-VTA treatment) and drug treatment (cortagine vs vehicle) as factors showed a significant overall main effect of reinstatement $\left(F_{(1,4)}=\right.$ 17.316, $p<0.05)$, but not cortagine treatment, and a significant reinstatement $\times$ cortagine treatment interaction $\left(F_{(1,4)}=7.626\right.$, $p=0.05)$. By contrast, an identical analysis examining rUCN II-induced reinstatement failed to show effects of rUCN II treat$\left({ }^{\#} p<0.05\right.$ vs Veh).
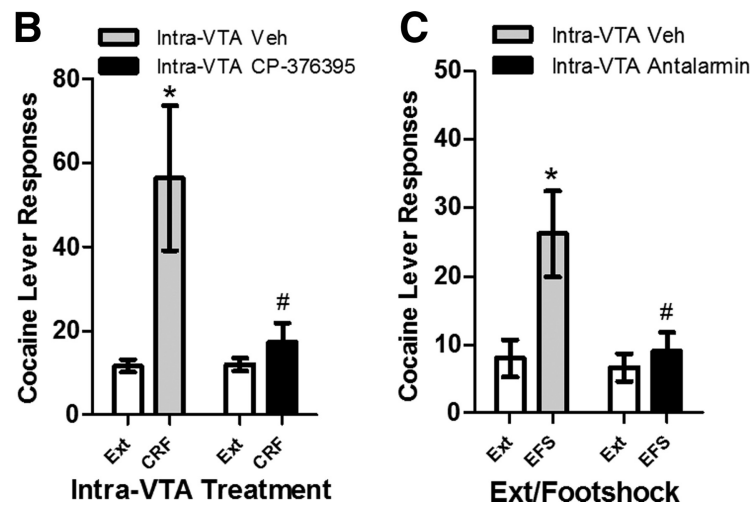

Figure 3. Effects of intra-VTA injections of CRF-R1 antagonists on reinstatement by intra-VTA CRF delivery and footshock stress in $L g A$ rats. $A, B$, Data represent the effects of bilateral injections of antalarmin $(A, 500 \mathrm{ng} / \mathrm{side} ; n=7),(P-376395(B, 500 \mathrm{ng} / \mathrm{side}$; $n=6)$, or vehicle on reinstatement by bilateral intra-VTA delivery of (RF ( $500 \mathrm{ng} / \mathrm{side})$ and the effects of bilateral injections of (

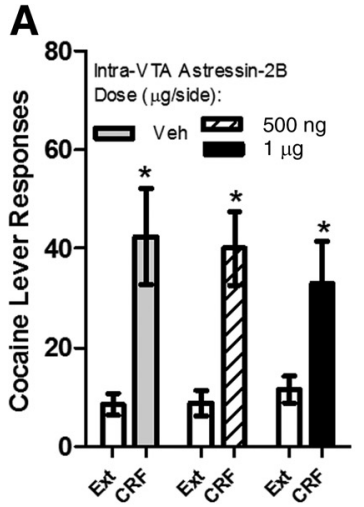

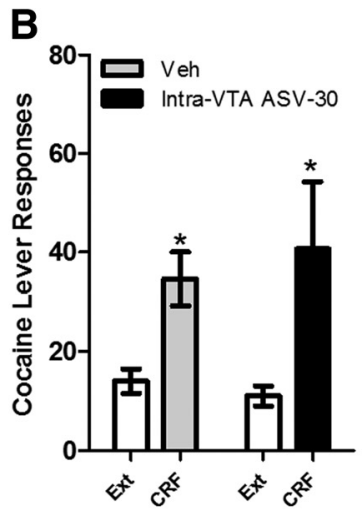

Intra-VTA Treatment

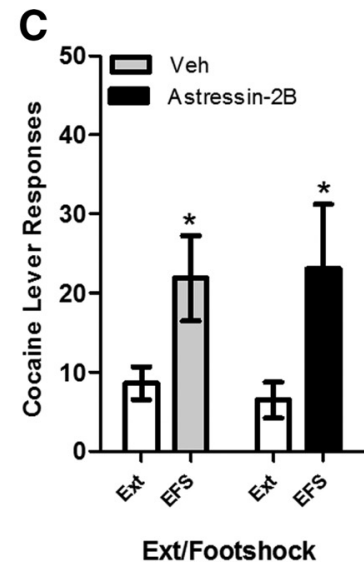
ng/side; $n=6)$, or vehicle on reinstatement by bilateral intra-VTA delivery of CRF ( $500 \mathrm{ng} / \mathrm{side})$ and the effects of bilateral injections of astressin- $2 \mathrm{~B}(500 \mathrm{ng} / \mathrm{side}$ ) on reinstatement (responses $/ 2 \mathrm{~h}$ session $\pm \mathrm{SE}$ ) by electric footshock $(C, n=8)$. In all cases, significant reinstatement was observed in rats pretreated with vehicle or CRF-R2 antagonists [ ${ }^{*} p<0.05$ vs extinction (Ext)], while CRF-R2 antagonist pretreatments failed to attenuate reinstatement by intra-VTA CRF or shock.

ment or reinstatement testing or a $\mathrm{rUCN}$ II $\times$ reinstatement testing interaction. Intra-VTA cortagine treatment increased responding compared with the preceding extinction session $(p<$ $0.05)$ and with vehicle-treated rats $(p<0.05)$.

\section{Discussion}

We have reported that self-administration under LgA/highintake conditions augments later reinstatement by footshock stress and intracerebroventricular CRF (Mantsch et al., 2008), and that footshock-induced reinstatement following $\operatorname{LgA}$ self-administration is CRF dependent (Graf et al., 2011). These findings are consistent with prior reports that stress-induced reinstatement of drug seeking following self-administration of cocaine (Erb et al., 1998), heroin (Shaham et al., 1997), alcohol (Lê et al., 2000), or nicotine (Bruijnzeel et al., 2009) involves CRF, as does stress-induced reinstatement of palatable food-seeking behavior (Ghitza et al., 2006). Our current findings demonstrate that heightened CRF responsiveness in the VTA likely contributes to intake-dependent increases in vulnerability to stress- 


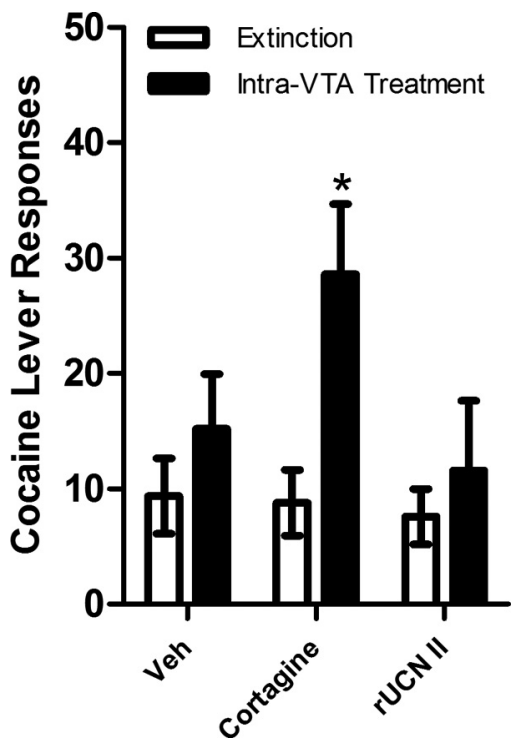

Figure 5. Reinstatement by intra-VTA administration of the (RF-R1-selective agonist cortagine and the CRF-R2-selective agonist rUCN II in LgA rats $(n=5)$. Cortagine (100 ng/side), but not UCN II (250 ng/side) or vehicle, reinstated extinguished cocaine seeking $\left({ }^{*} p<0.05\right.$ vs vehicle and the preceding extinction session). The data represent responding on the cocaine lever (responses $/ 2 \mathrm{~h}$ session $\pm \mathrm{SE}$ ) during extinction or following bilateral intra-VTA cortagine or Veh treatment.

induced relapse that emerge with repeated drug use. Previous studies have reported that VTA CRF levels are increased during stress-induced reinstatement and that stress-induced cocaine seeking involves CRF actions in the VTA (Wang et al., 2005, 2007). Here we report that, similar to stress-induced reinstatement, reinstatement by intra-VTA CRF was augmented, and in fact was only observed, in rats with a history of selfadministration under LgA/high-intake conditions. Further, we find that cocaine seeking induced by CRF delivery into the VTA or by footshock is mediated by VTA CRF-R1 and not CRF-R2, a finding that contrasts with previous reports implicating CRF-R2 in the VTA in stress-induced reinstatement (Wang et al., 2005, 2007).

A circuit involving the regulation of VTA dopaminergic neurons that project to the dorsal medial prefrontal cortex has been implicated in stress-induced relapse (McFarland et al., 2004). According to this model, inputs from several regions, including the ventral bed nucleus of the stria terminalis (vBNST), the central nucleus of the amygdala (CeA), and the NAc shell positively regulate mesocortical dopamine neurons in the VTA, thereby promoting cocaine seeking through activation of corticostriatal glutamatergic inputs into the NAc core. It has been reported that the VTA receives CRF-containing afferents from two of these regions, the CeA and vBNST (Rodaros et al., 2007), and dual immunolabeling studies indicate that these CRF-containing projections are primarily glutamatergic (Tagliaferro and Morales, 2008). CRF-containing afferents form synapses on dopaminergic and GABAergic cells in the VTA (Tagliaferro and Morales, 2008), and the activity of both cell types is altered upon local CRF application (Korotkova et al., 2006). In the case of dopaminergic cells, CRF-positive synapses are primarily asymmetric (Tagliaferro and Morales, 2008), suggesting that CRF-releasing glutamatergic projections into the VTA, likely originating in the vBNST and $\mathrm{CeA}$, positively regulate the activity of dopaminergic cells. Accordingly, delivery of CRF into the VTA stimulates local and terminal field dopamine release (Kalivas et al., 1987; Wang et al., 2005).

Although CRF-R1s are abundant in the VTA, their expression on dopaminergic cells appears to be somewhat limited (Korotkova et al., 2006), suggesting that actions of CRF on nondopaminergic cells may contribute to its effects on cocaine seeking. GABAergic cells in the VTA have also been reported to express CRF-R1s (Korotkova et al., 2006). The pattern of expression on other cell types in the VTA (glial cells, glutamatergic neurons) is unknown. The picture is less clear for CRF-R2s. Despite pharmacological evidence for CRF-R2 expression in the VTA (Wang et al., 2007), examination of the VTA using in situ hybridization suggests that there is little or no cell body expression (Van Pett et al., 2000). However, CRF-R2 expression has been reported as determined by RT-PCR (Korotkova et al., 2006). The purported ability of CRF-R2s to locally regulate glutamate release suggests a potential presynaptic localization of CRF-R2s on glutamate terminals (Wang et al., 2007). A clear understanding of the localization of CRF-R2s in the VTA awaits the availability of better antibodies for immunohistochemical characterization.

The precise mechanism of CRF regulation of dopaminergic cells in the VTA is also unclear and has been reported to involve both CRF-R1-mediated activation of protein kinase C (PKC) (Wanat et al., 2008) and possibly PKA (Riegel and Williams, 2008) signaling and/or CRF-R2 facilitation of NMDA receptor function (Ungless et al., 2003). The CRF-R2 effects on signaling also appear to require CRF interaction with CRF binding protein (Ungless et al., 2003; Wang et al., 2005) and may also involve presynaptic enhancement of glutamate release (Wang et al., 2005, 2007).

While our data implicate CRF actions in the VTA in stressinduced reinstatement, others have reported that CRF can act elsewhere within this circuit, including at sites upstream from the VTA, to regulate cocaine seeking, most notably in the vBNST, where CRF receptor antagonism blocks stress-induced cocaine seeking (Erb and Stewart, 1999). As the CRF actions in the vBNST involve projections from the CeA (Erb et al., 2001) and both regions send CRF-containing efferents to the VTA (Rodaros et al., 2007), it is likely that CRF exerts actions at multiple sites in the circuit that contribute to stress-induced cocaine seeking.

Similar to what we previously reported with stress-induced reinstatement (Mantsch et al., 2008), reinstatement by intra-VTA CRF appeared to represent an emergent phenomenon in that it was only observed following LgA self-administration. This finding is consistent with a report by Wang et al. (2005), who found that while footshock-induced increases in VTA CRF were observed in the VTA, the ability of CRF to regulate dopamine and glutamate levels in the VTA required a history of cocaine selfadministration. The apparent augmentation of CRF responsiveness is also consistent with reports that CRF responsiveness in a number of brain regions is heightened following repeated cocaine administration (Erb et al., 2005; Liu et al., 2005; Pollandt et al., 2006; Orozco-Cabal et al., 2008; Francesconi et al., 2009; Guan et al., 2009). Although the effects of LgA cocaine self-administration on CRF-R1-mediated actions in the VTA have not been examined, some insight into potential mechanisms underlying heightened CRF regulation of cocaine seeking can be provided by studies involving repeated experimenter-delivered cocaine. In the VTA, CRF-R1 activation has been reported to produce both excitatory effects (via potentiation of NMDA and AMPA receptor-mediated neurotransmission) (Hahn et al., 2009) and inhibitory effects (via enhancement of D2 dopamine- and $\mathrm{GABA}_{\mathrm{B}}$-receptor mediated regulation of G-protein-activated in- 
wardly rectifying potassium channels) (Beckstead et al., 2009) on dopaminergic neurons. With repeated cocaine exposure, the excitatory effects of CRF-R1 activation are augmented (Hahn et al., 2009), while the inhibitory effects diminish (Beckstead et al., 2009), likely resulting in a net shift toward positive CRF-R1 regulation of dopaminergic cells in the VTA. Further, CRF binding in the VTA, as measured using autoradiography, is increased with repeated cocaine delivery (Goeders et al., 1990).

Our findings that VTA CRF-R1s mediate CRF- and stressinduced cocaine seeking are inconsistent with previous reports suggesting involvement of CRF-R2s in the VTA, apparently through a mechanism that also involves CRF binding protein (Wang et al., $2005,2007)$. However, others have reported that stress-induced reinstatement is inhibited by systemic or intracerebroventricular delivery of CRF-R1, but not CRF-R2, antagonists (Shaham et al., 1998; Lu et al., 2001) and that CRF-R1, but not CRF-R2, antagonism can reduce evoked increases in VTA and NAc dopamine (Lu et al., 2003; Lodge and Grace, 2005). The reason for the discrepancy between our findings and those of Wang et al. $(2005,2007)$ is unclear but may involve different modes of CRF and receptor antagonist delivery (microinjection vs reverse dialysis), different CRF receptor antagonist and agonist doses, different rat strains, and differential experimental histories. Most importantly, it may be that the regulation of cocaine seeking by CRF-R1 in VTA requires a history of very high levels of cocaine intake [the daily cocaine intake reported by Wang et al. $(2005,2007)$ was $\sim 33 \mathrm{mg} / \mathrm{kg}$ compared with $>70 \mathrm{mg} / \mathrm{kg}$ in our LgA rats], which is consistent with reports that the selective CRF-R1 antagonists antalarmin and N,N-bis(2-methoxyethyl)-3(4-methoxy-2-methylphenyl)-2,5-dimethyl-pyrazolo[1,5a]pyrimidin-7-amine (MPZP) only reduce cocaine self-administration following escalation in LgA rats (Specio et al., 2008).

The ability of stressful life events to precipitate drug use through actions involving CRF-R1s in the VTA may represent an emergent consequence of excessive cocaine use. Identification of the precise mechanisms through which VTA CRF-R1 activation produces cocaine seeking and the neuroadaptations that contribute to heightened susceptibility to CRF-dependent reinstatement should provide important insight into how stressor responsiveness changes in cocaine addicts in a way that promotes further use.

\section{References}

Ahmed SH, Koob GF (1997) Cocaine- but not food-seeking behavior is reinstated by stress after extinction. Psychopharmacology 132:289-295.

Ahmed SH, Koob GF (1998) Transition from moderate to excessive drug intake: change in hedonic set point. Science 282:298-300.

Beckstead MJ, Gantz SC, Ford CP, Stenzel-Poore MP, Phillips PE, Mark GP, Williams JT (2009) CRF enhancement of GIRK channel-mediated transmission in dopamine neurons. Neuropsychopharmacology 34:1926-1935.

Bruijnzeel AW, Prado M, Isaac S (2009) Corticotropin-releasing factor-1 receptor activation mediates nicotine withdrawal-induced deficit in brain reward function and stress-induced relapse. Biol Psychiatry 66:110-117.

Chen YL, Obach RS, Braselton J, Corman ML, Forman J, Freeman J, Gallaschun RJ, Mansbach R, Schmidt AW, Sprouse JS, Tingley Iii FD, Winston E, Schulz DW (2008) 2-aryloxy-4-alkylaminopyridines: discovery of novel corticotropin-releasing factor 1 antagonists. J Med Chem 51:1385-1392.

Erb S, Stewart J (1999) A role for the bed nucleus of the stria terminalis, but not the amygdala, in the effects of corticotropin-releasing factor on stressinduced reinstatement of cocaine seeking. J Neurosci 19:RC35.

Erb S, Shaham Y, Stewart J (1996) Stress reinstates cocaine-seeking behavior after prolonged extinction and a drug-free period. Psychopharmacology 128:408-412.

Erb S, Shaham Y, Stewart J (1998) The role of corticotropin-releasing factor and corticosterone in stress- and cocaine-induced relapse to cocaine seeking in rats. J Neurosci 18:5529-5536.
Erb S, Salmaso N, Rodaros D, Stewart J (2001) A role for the CRFcontaining pathway from central nucleus of the amygdala to bed nucleus of the stria terminalis in the stress-induced reinstatement of cocaine seeking in rats. Psychopharmacology 158:360-365.

Erb S, Funk D, Lê AD (2005) Cocaine pre-exposure enhances CRF-induced expression of c-fos mRNA in the central nucleus of the amygdala: an effect that parallels the effects of cocaine pre-exposure on CRF-induced locomotor activity. Neurosci Lett 383:209-214.

Erb S, Petrovic A, Yi D, Kayyali H (2006) Central injections of CRF reinstate cocaine seeking in rats after postinjection delays of up to $3 \mathrm{~h}$ : an influence of time and environmental context. Psychopharmacology 187:112-120.

Forster GL, Pringle RB, Mouw NJ, Vuong SM, Watt MJ, Burke AR, Lowry CA, Summers CH, Renner KJ (2008) Corticotropin-releasing factor in the dorsal raphe nucleus increases medial prefrontal cortical serotonin via type 2 receptors and median raphe nucleus activity. Eur J Neurosci 28:299-310.

Fox HC, Talih M, Malison R, Anderson GM, Kreek MJ, Sinha R (2005) Frequency of recent cocaine and alcohol use affects drug craving and associated responses to stress and drug-related cues. Psychoneuroendocrinology 30:880-891.

Francesconi W, Berton F, Repunte-Canonigo V, Hagihara K, Thurbon D, Lekic D, Specio SE, Greenwell TN, Chen SA, Rice KC, Richardson HN, O’Dell LE, Zorrilla EP, Morales M, Koob GF, Sanna PP (2009) Protracted withdrawal from alcohol and drugs of abuse impairs long-term potentiation of intrinsic excitability in the juxtacapsular bed nucleus of the stria terminalis. J Neurosci 29:5389-5401.

Ghitza UE, Gray SM, Epstein DH, Rice KC, Shaham Y (2006) The anxiogenic drug yohimbine reinstates palatable food seeking in a rat relapse model: a role of CRF1 receptors. Neuropsychopharmacology 31:2188-2196.

Goeders NE, Bienvenu OJ, De Souza EB (1990) Chronic cocaine administration alters corticotrophin releasing factor receptors in the rat brain. Brain Res 531:322-328.

Graf EN, Hoks MA, Baumgardner J, Sierra J, Vranjkovic O, Bohr C, Baker DA, Mantsch JR (2011) Adrenal activity during repeated long-access cocaine self-administration is required for later CRF-induced and CRFdependent stressor-induced reinstatement in rats. Neuropsychopharmacology 36:1444-1454.

Guan X, Zhang R, Xu Y, Li S (2009) Cocaine withdrawal enhances longterm potentiation in rat hippocampus via changing the activity of corticotropin-releasing factor receptor subtype 2. Neuroscience 161:665-670.

Hahn J, Hopf FW, Bonci A (2009) Chronic cocaine enhances corticotropinreleasing factor-dependent potentiation of excitatory transmission in ventral tegmental area dopamine neurons. J Neurosci 29:6535-6544.

Henry B, Vale W, Markou A (2006) The effect of lateral septum corticotropin-releasing factor receptor 2 activation on anxiety is modulated by stress. J Neurosci 26:9142-9152.

Kalivas PW, Duffy P, Latimer LG (1987) Neurochemical and behavioral effects of corticotropin-releasing factor in the ventral tegmental area of the rat. J Pharmacol Exp Ther 242:757-763.

Korotkova TM, Brown RE, Sergeeva OA, Ponomarenko AA, Haas HL (2006) Effects of arousal- and feeding-related neuropeptides on dopaminergic and GABAergic neurons in the ventral tegmental area of the rat. Eur J Neurosci 23:2677-2685.

Lê AD, Harding S, Juzytsch W, Watchus J, Shalev U, Shaham Y (2000) The role of corticotrophin-releasing factor in stress-induced relapse to alcohol-seeking behavior in rats. Psychopharmacology 150:317-324.

Liu J, Yu B, Orozco-Cabal L, Grigoriadis DE, Rivier J, Vale WW, ShinnickGallagher P, Gallagher JP (2005) Chronic cocaine administration switches corticotropin-releasing factor2 receptor-mediated depression to facilitation of glutamatergic transmission in the lateral septum. J Neurosci 25:577-583.

Lodge DJ, Grace AA (2005) Acute and chronic corticotropin-releasing factor 1 receptor blockade inhibits cocaine-induced dopamine release: correlation with dopamine neuron activity. J Pharmacol Exp Ther 314: 201-206.

Lu L, Liu D, Ceng X (2001) Corticotropin-releasing factor receptor type 1 mediates stress-induced relapse to cocaine-conditioned place preference in rats. Eur J Pharmacol 415:203-208.

Lu L, Liu Z, Huang M, Zhang Z (2003) Dopamine-dependent responses to 
cocaine depend on corticotropin-releasing factor receptor subtypes. J Neurochem 84:1378-1386.

Mantsch JR, Baker DA, Francis DM, Katz ES, Hoks MA, Serge JP (2008) Stressor- and corticotropin releasing factor-induced reinstatement and active stress-related behavioral responses are augmented following longaccess cocaine self-administration by rats. Psychopharmacology 195:591-603.

McFarland K, Davidge SB, Lapish CC, Kalivas PW (2004) Limbic and motor circuitry underlying footshock-induced reinstatement of cocaine-seeking behavior. J Neurosci 24:1551-1560.

Orozco-Cabal L, Liu J, Pollandt S, Schmidt K, Shinnick-Gallagher P, Gallagher JP (2008) Dopamine and corticotropin-releasing factor synergistically alter basolateral amygdala-to-medial prefrontal cortex synaptic transmission: functional switch after chronic cocaine administration. J Neurosci 28:529-542.

Paxinos G, Watson C (1998) The rat brain in stereotaxic coordinates, 4th Ed. San Diego: Academic.

Pollandt S, Liu J, Orozco-Cabal L, Grigoriadis DE, Vale WW, Gallagher JP, Shinnick-Gallagher P (2006) Cocaine withdrawal enhances long-term potentiation induced by corticotropin-releasing factor at central amygdala glutamatergic synapses via CRF, NMDA receptors and PKA. Eur J Neurosci 24:1733-1743.

Reyes TM, Lewis K, Perrin MH, Kunitake KS, Vaughan J, Arias CA, Hogenesch JB, Gulyas J, Rivier J, Vale WW, Sawchenko PE (2001) Urocortin II: a member of the corticotropin-releasing factor (CRF) neuropeptide family that is selectively bound by type 2 CRF receptors. Proc Natl Acad Sci U S A 98:2843-2848.

Riegel AC, Williams JT (2008) CRF facilitates calcium release from intracellular stores in midbrain dopamine neurons. Neuron 57:559-570.

Rodaros D, Caruana DA, Amir S, Stewart J (2007) Corticotropin-releasing factor projections from limbic forebrain and paraventricular nucleus of the hypothalamus to the region of the ventral tegmental area. Neuroscience 150:8-13.

Shaham Y, Funk D, Erb S, Brown TJ, Walker CD, Stewart J (1997) Corticotropin-releasing factor, but not corticosterone, is involved in stress-induced relapse to heroin-seeking in rats. J Neurosci 17:2605-2614.

Shaham Y, Erb S, Leung S, Buczek Y, Stewart J (1998) CP-154,526, a selective, non-peptide antagonist of the corticotropin-releasing factorl receptor attenuates stress-induced relapse to drug seeking in cocaine- and heroin-trained rats. Psychopharmacology 137:184-190.

Shalev U, Erb S, Shaham Y (2010) Role of CRF and other neuropeptides in stress-induced reinstatement of drug seeking. Brain Res 1314:15-28.
Sinha R, Catapano D, O’Malley S (1999) Stress-induced craving and stress response in cocaine dependent individuals. Psychopharmacology 142:343-351.

Specio SE, Wee S, O’Dell LE, Boutrel B, Zorrilla EP, Koob GF (2008) CRF(1) receptor antagonists attenuate escalated cocaine self-administration in rats. Psychopharmacology 196:473-482.

Tagliaferro P, Morales M (2008) Synapses between corticotropin-releasing factor-containing axon terminals and dopaminergic neurons in the ventral tegmental area are predominantly glutamatergic. J Comp Neurol 506:616-626.

Tezval H, Jahn O, Todorovic C, Sasse A, Eckart K, Spiess J (2004) Cortagine, a specific agonist of corticotropin-releasing factor receptor subtype 1 , is anxiogenic and antidepressive in the mouse model. Proc Natl Acad Sci U S A 101:9468-9473.

Ungless MA, Singh V, Crowder TL, Yaka R, Ron D, Bonci A (2003) Corticotropin-releasing factor requires $\mathrm{CRF}$ binding protein to potentiate NMDA receptors via CRF receptor 2 in dopamine neurons. Neuron 39:401-407.

Van Pett K, Viau V, Bittencourt JC, Chan RK, Li HY, Arias C, Prins GS, Perrin M, Vale W, Sawchenko PE (2000) Distribution of mRNAs encoding CRF receptors in brain and pituitary of rat and mouse. J Comp Neurol 428:191-212.

Wanat MJ, Hopf FW, Stuber GD, Phillips PE, Bonci A (2008) Corticotropin-releasing factor increases mouse ventral tegmental area dopamine neuron firing through a protein kinase $\mathrm{C}$-dependent enhancement of Ih. J Physiol 586:2157-2170.

Wang B, Shaham Y, Zitzman D, Azari S, Wise RA, You ZB (2005) Cocaine experience establishes control of midbrain glutamate and dopamine by corticotropin-releasing factor: a role in stress-induced relapse to drug seeking. J Neurosci 25:5389-5396.

Wang B, You ZB, Rice KC, Wise RA (2007) Stress-induced relapse to cocaine seeking: roles for the $\mathrm{CRF}(2)$ receptor and CRF-binding protein in the ventral tegmental area of the rat. Psychopharmacology 193:283-294.

Webster EL, Lewis DB, Torpy DJ, Zachman EK, Rice KC, Chrousos GP (1996) In vivo and in vitro characterization of antalarmin, a nonpeptide corticotropin-releasing hormone $(\mathrm{CRH})$ receptor antagonist: suppression of pituitary ACTH release and peripheral inflammation. Endocrinology 137:5747-5750

Wise RA, Morales M (2010) A ventral tegmental CRF-glutamate-dopamine interaction in addiction. Brain Res 1314:38-43. 